Jorge Rafael Gonzalez-Teodoro - Enrique Romero-Cadaval - Rafael Asensi - Vladimir Kindl

\title{
EOUIVALENT ELECTRICAL MODEL OF AN INDUCTOR EXCITED BY A TRIANGULAR CURRENT INCLUDING SATURATION
}

A model for an equivalent electrical circuit designed for a ferrite (3C90) inductor usually used in power converters excited by a non-sinusoidal current appropriate for use in power electronics is proposed. This study, based on $3 D$ finite element analysis, leads to significant precision advantages over $2 D$ analysis for non-symmetric inductors. The frequency range of the analysis for the toroidal core was between $15 \mathrm{kHz}$ and $1 \mathrm{GHz}$, with different levels of excitation in non-saturation and saturation status focusing on the power loss.

Keywords: ferrite inductors, $3 d$ finite element analysis, power losses, saturation, hysteresis, eddy current losses, magnetization

\section{Introduction}

Ferrites (3C90) are common used due to their losses data and permeability characteristics [1-6] in power converters. These components have non-linear behaviour that needs to be added in electromagnetic analysis to develop a transient simulation of these power converters [7-11]. Models of these magnetic components can be found in the bibliography [12-14], However, non-linear models that represent non-linear behaviour is an an absence of power converterfield. An electrical-magnetic model of a ferrite inductor valid for triangular current excitations is presented for a $15 \mathrm{kHz}$ to $1 \mathrm{GHz}$ frequency range (the range of switching frequencies used by power electronic converters based on $\mathrm{Si}, \mathrm{SiC}$ or GaN semiconductors) with different signals to include the saturation status in the analysis.

The core for the inductor component analysed in this work was toroidal because they are common in transformers and inductive components, they do not have symmetry and they cannot be solved using Maxwell's equations in either 1D or 2D finite element analysis (FEA).

A comparison between sinusoidal and triangular excitation currents for the inductor component is included in the analysis as well.

Section II explains the FEM procedure, Section describes the signals used in this study and Section IV is the definition of core loss used for the scripts in the FEM software. At the end, the conclusions from the FEM results are presented.

\section{Procedure for parameter extraction}

This work aims to achieve inductance, $L$, and resistance, $R$, it means, the parameters of the the equivalent circuit for the analysed inductor to obtain the output voltage and current waveform for an input triangular current excitation utilised in the inductor component. The inducatance and the resistance connect in series. $L$ depends on the excitation current, $I=f(L, I)$, and $R$ depends on the $I_{r m s}$ and frequency, $R=f\left(I_{r m s}\right.$, freq. $)$ being non linear components.

To develop the parameter extraction, a 3D component without simplifications was analysed using FEM analysis (Transient Solver with 2\% energy error in Maxwell Ansys to obtain the convergence), which involves three different steps: pre-modelling, simulation and post-modelling phases. If the computational limitations do not allow convergence in the FEM simulation, a simplification model is described in [15].

$L$ was estimated applying a triangular current and the $\mathrm{BH}$ data [16] in the pre-modelling that characterizes the core material. After the simulation, the $L-I$ curve described in [17] can be defined the following parameter ( $\phi$ - $I$ curve):

$$
L(I)=\frac{d \phi}{d I}
$$

where $\phi$ is the magnetic flux.

$\mathrm{R}$ was derived during the post- modelling step $\mathrm{R}-\mathrm{I}_{r m s}$ curve as described in [17]

\footnotetext{
Jorge Rafael Gonzalez-Teodoro ${ }^{1, *}$, Enrique Romero-Cadaval ${ }^{1}$, Rafael Asensi' ${ }^{2}$ Vladimir Kindl $^{3}$

${ }^{1}$ University of Extremadura, Badajoz, Spain

${ }^{2}$ Politecnica de Madrid, Spain

${ }^{3}$ University of West Bohemia, Pilsen, Czech Republic

*E-mail of corresponding author: jordirgt@hotmail.com
} 


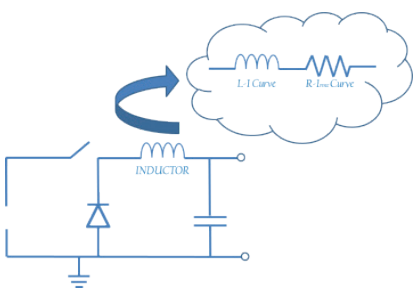

a)

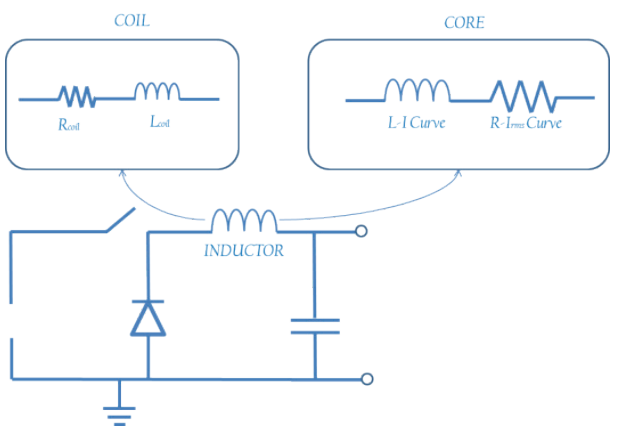

b)

Figure 1 Equivalent circuit in Saturation and non-saturation: a) Model 1, b) Model 2

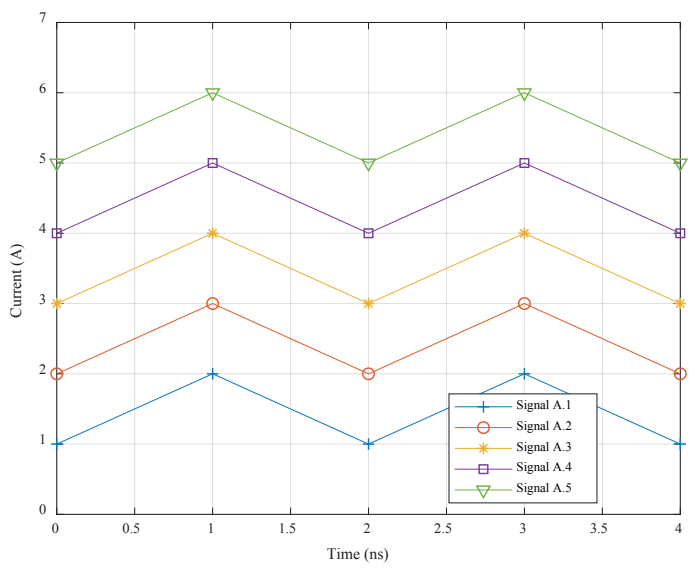

Figure 2 Triangular signals, Type A

$R=\frac{\bar{P}}{I_{r m s}^{2}}$

where $\bar{P}$ is the average value of the power and $I_{r m s}$ is the rms value of the current.

The equivalent resistance of a magnetic component is normally defined as the resistance for a sinusoidal signal instead of a triangular current signal. Nevertheless, the resistance discussed in this work is the average resistance for a triangular signal in a transient analysis developed by FEM.

The inductor component studied is shown in Figure 1(a) (Model 1). This model is valid for saturation and nonsaturation status.

In the case of non-saturation and core linear behaviour, it is possible to add the $R$ and $L$ for the winding in the model. See Figure 1(b) (Model 2). These parameters were obtained during the 3D FEM post-modelling, using the procedure in [18] and Equations (3)-(4) to obtain the coefficients for any frequency range for the winding parameters considering a linear system because the superposition theorem was used for deriving the values of the parameters.

In summation, in saturation status, Model 1(a) is used because the core power loss is dominant over other parameters. Model 1(b) is selected for non-saturation including the winding parameters in the equivalent circuit of the inductor component.

$L_{i j}=\frac{1}{I_{0}^{2}} \oiiint_{V} \operatorname{Re}\left(\vec{B}_{i o} \cdot \vec{H}_{j o}^{*}\right) d v$

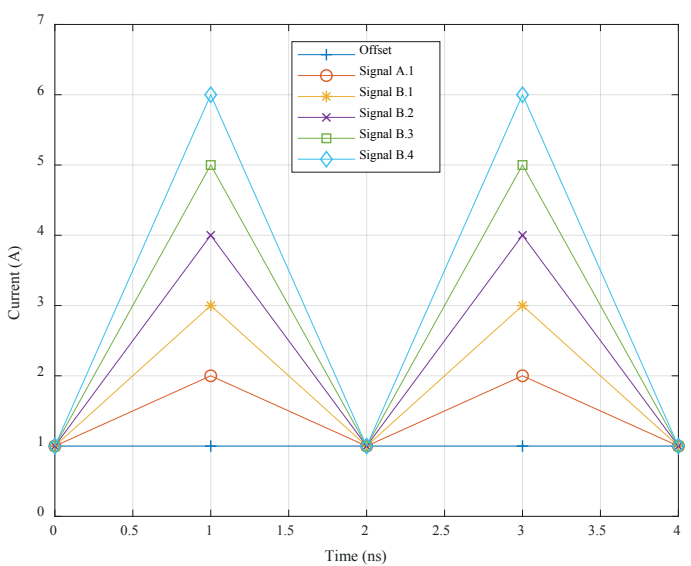

Figure 3 Triangular signals, Type $B$

$R_{i j}=\frac{1}{I_{0}^{2}} \oiiint_{V} \frac{1}{\sigma} \cdot \operatorname{Re}\left(\vec{J}_{i o} \cdot \vec{J}_{j o}^{*}\right) d v$

\section{Signals description}

\subsection{Triangular signals}

Different triangular signals (type A and B) were analysed.

Signal type A is a triangular signal with different offsets and type B is a triangular signal with the same offset, varying the peak value. See Figures 2-3. In total, 9 different triangular signals were analysed.

The $I_{r m s}$ for each analysed signal are indicated in Table 1, where A.3, A.4 and A.5 produce core saturation according to the manufacturer's datasheet.

\subsection{Sinusoidal signal}

The sinusoidal signal selected for comparison with the triangular signal is shown in Figure 4 and Table 2 for the $I_{r m s}$ of this signal and the corresponding triangular signal. Signal C.1 was set to have the most similar $\mathrm{rms}$ value with the triangular signal chosen (signal A.1). All the signals shown are repeated from the frequency range studied. 
Table 1 RMS value for different signals

\begin{tabular}{ccc}
\hline Signal Name & $I_{r m s}(A)$ & $B(T)$ \\
\hline A.1 & 1.286 & 0.244 \\
B.1 & 1.570 & 0.292 \\
B.2 & 1.856 & 0.341 \\
B.3 & 2.141 & 0.365 \\
A.2 & 2.286 & 0.333 \\
B.4 & 2.426 & 0.382 \\
A.3 & 3.286 & 0.4 \\
A.4 & 4.286 & 0.444 \\
A.5 & 5.286 & 0.462 \\
\hline
\end{tabular}

Table 2 RMS value for triangular/sinusoidal signal

\begin{tabular}{ccc}
\hline & A.1 & C.1 \\
\hline $\mathrm{I}_{\mathrm{rms}}(\mathrm{A})$ & 1.286 & 1.354 \\
\hline
\end{tabular}

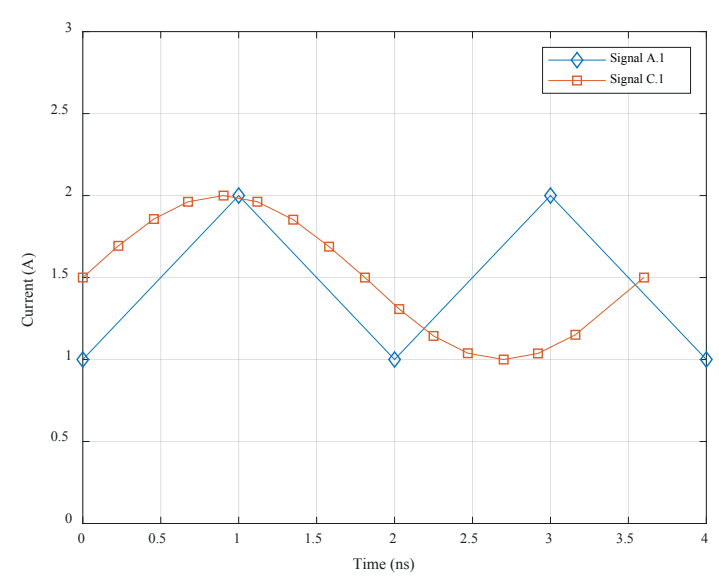

Figure 4 Triangular signals, Type A, and corresponding sinusoidal signal, Type $C$

\section{Determination of the core power loss}

The core loss calculated by Maxwell Ansys uses the Steinmetz equation with parameters defined by Ansys or modified by the user. This formula presents several issues, the method is only for static, does not predict important frequency/rate dependency and, in addition to linear dynamics, does not capture non-linearity in excess loss [19].

Nevertheless, Ansys Maxwell permits calculating the power loss separately (5), including the hysteresis loop data in the pre-modelling by transient analysis solver.

$P_{t}=P_{\text {hysteresis }}+P_{\text {eddy }}$.

There is another loss, $P_{\text {anomalous }}$ (loss due to the material properties modification due to the eddy current); however, for this particular case, it is negligible for the eddy current produced in the ferrite core component.

\subsection{Hysteresis loss}

During each AC cycle, current flowing in the forward and reverse directions alternatively magnetizes and demagnetizes the core. Energy is lost in each hysteresis cycle within the magnetic core. Energy loss is dependent on the properties (e.g. coercivity) of the core material and is proportional to the area of the hysteresis loop [16]. The calculation during post-modelling is defined by [20]:

$$
P_{\text {hysteresis }}=\int_{\text {vol }} \frac{1}{2} \cdot \omega \cdot \operatorname{Im}\left(B \cdot H^{*}\right) d V,
$$

where $\vec{B}$ is the magnetic flux density, $\vec{H}^{*}$ is the complex conjugate of the magnetic field and $\omega$ is the angular frequency.

\subsection{Eddy current loss}

An eddy current is an electric current set up by an alternating magnetic field. Thus, if the core is manufactured 
Table 3 Dissipated energy vs Irms

\begin{tabular}{ccccccccccc}
\hline $\mathrm{B}(\mathrm{T})$ & 0.244 & 0.292 & 0.341 & 0.365 & 0.333 & 0.382 & 0.4 & 0.444 & 0.462 \\
\hline $\mathrm{I}_{\text {rms }}(\mathrm{A})$ & 1.286 & 1.570 & 1.856 & 2.141 & 2.286 & 2.426 & 3.286 & 4.286 & 5.286 \\
$\mathrm{E}_{\text {surf }}(\mathrm{J})$ & 0.063 & 0.122 & 0.163 & 0.173 & 0.37 & 0.265 & 0.71 & 1.497 & 1.723 \\
$\mathrm{E}_{\text {core }}(\mathrm{J})$ & $2 \mathrm{E}-12$ & $3 \mathrm{E}-12$ & $5 \mathrm{E}-12$ & $8 \mathrm{E}-12$ & $4 \mathrm{E}-12$ & $1 \mathrm{E}-11$ & $8 \mathrm{E}-12$ & $1 \mathrm{E}-11$ & $2 \mathrm{E}-11$ \\
$\mathrm{E}_{\text {hys }}(\mathrm{J})$ & 0.0001 & 0.0001 & 0.0001 & 0.0001 & 0.0001 & 0.0001 & 0.0027 & 0.0035 & 0.0041 \\
\hline
\end{tabular}

Table 4 Values of coefficients for $k$ vs Irms

\begin{tabular}{cccc}
\hline & $\mathrm{k}_{\mathrm{S}}$ & $\mathrm{k}_{\mathrm{C}}$ & $\mathrm{k}_{\mathrm{H}}$ \\
\hline Non-saturation & $0.036-\mathrm{I}_{\mathrm{rms}}^{2.5}$ & $2 \cdot 10^{-12} \cdot \mathrm{I}_{\mathrm{rms}}^{1.4}$ & 0.0001 \\
Saturation & $0.036-\mathrm{I}_{\mathrm{rms}}^{2.5}$ & $2 \cdot 10^{-12} \cdot \mathrm{I}_{\mathrm{rms}}^{1.4}$ & $0.0008 \cdot \mathrm{I}_{\mathrm{rms}}$ \\
\hline
\end{tabular}

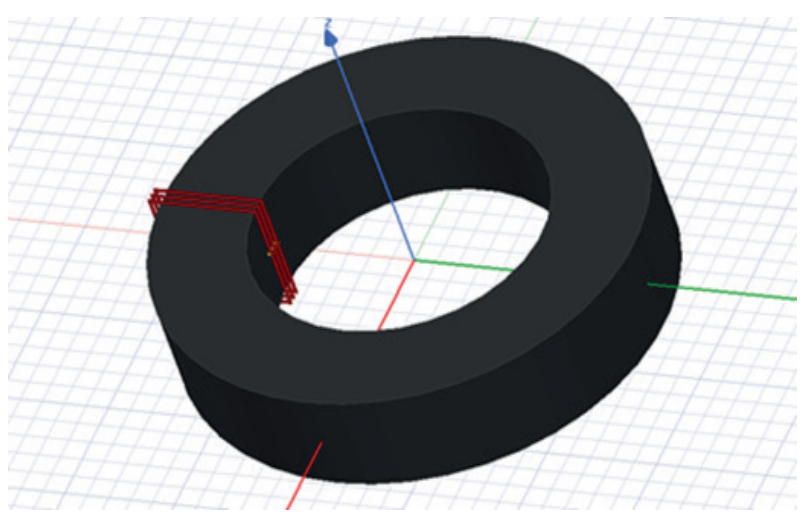

Figure 5 Inductor analyzed

with a conductor material, the eddy current losses arise modyfing the flux and producing circulatin current into the core. Eddy current loss depends upon the rate of change of flux as well as the resistance of the path. According to the theory, it expects that the loss changes with the square of both the maximum flux density and frequency if the core has been mmanufactured withferromagnetic materials. These currents, circulating in the core material cause resistive heating in this material [20]:

$$
P_{\text {core }}=\int_{v o l} \frac{1}{2 \sigma} \cdot \operatorname{Re}\left(J \cdot J^{*}\right) d V,
$$

where $J$ is the current density, $J^{*}$ is the complex conjugate of the current density and $\sigma$ is the material conductivity for the core. For the core surfaces, the eddy loss is given by [20]:

$$
P_{\text {surface }}=\sqrt{\frac{\omega \mu_{O} \mu_{r}}{8_{\sigma}}} \cdot \int H_{t} \cdot H_{t}^{*} d s
$$

where $\vec{H}_{t}$ is the tangential component of $\vec{H}$ on the boundary and $\vec{H}_{t}^{*}$ is the complex conjugate tangential component of $\vec{H}$ on the boundary.

Consequently, the total eddy current loss is defined as:

$$
P_{\text {eddy }}=P_{\text {core }}+P_{\text {surface }} .
$$

\section{Analysis using 3D FEM}

The selected Toroidal component core, C107.65.25 with 1 winding (4 turns with $1^{\circ}$ lateral distance) using a $3 \mathrm{C} 90$ material, has been chosen because it is a non-symmetric component [15] and 3D FEM analysis has more precision than 2D FEM analysis, see Figure 5.

The FEM analyses were performed with the magnetization choice selected for the core in the FEA tool solver to apply Equations (6)-(9) for calculating the losses.

The results for the 9 different triangular signals are shown in Appendix I, where the losses (hysteresis and eddy) and the magnetic field density peak for the different cases are presented. The hysteresis losses from signal Type $A$ become linear at high frequencies when the $I_{r m s}$ increases due to the magnetization impact. The hysteresis losses reach larger peaks than Type $B$ for cases where the peak current value is the same.

The eddy losses (surface) suffer an inrush effect to get to a constant value for Type $A$ signals. Type $B$ signals do not reach the saturation state on the core surface.

The eddy losses (core) have a sinusoidal behaviour according to the current for both types.

Since the analyses were developed from $15 \mathrm{kHz}$ to 1 $\mathrm{GHz}$, they can be used to calculate the dissipated energy. See Appendix II, where the energy from hysteresis losses and eddy current losses are shown. It is evidence that 


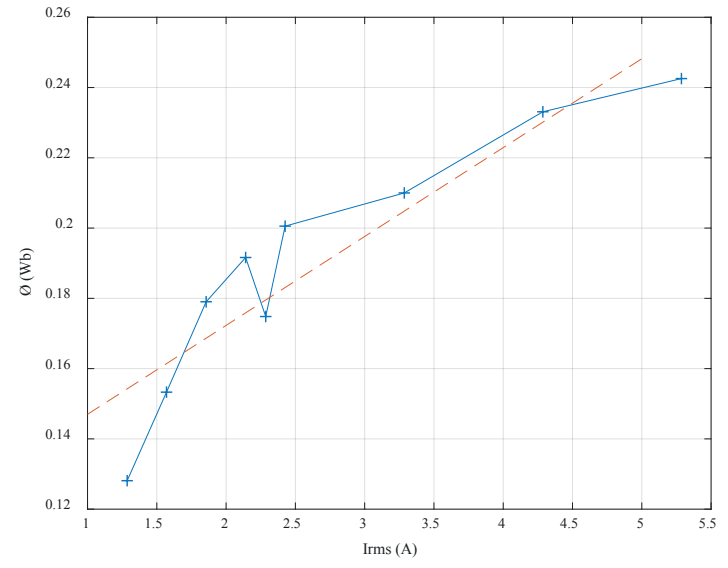

Figure 6 Relationship between $\phi$ and $I_{r m s}$

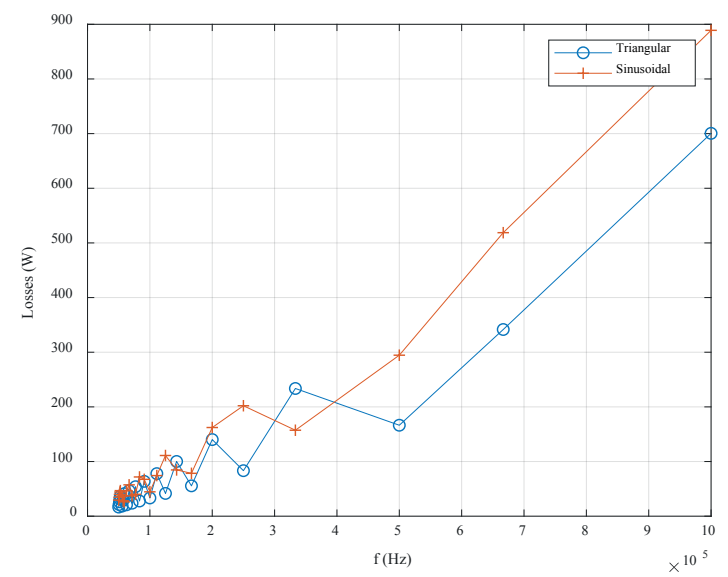

Figure 7 Comparison between A.1 and C.1 (Hysteresis Loss)

dissipated energy from eddy currents has a linear tendency but the energy from hysteresis currents has a quadratic one with the frequency.

See Table 3 for the dissipated energy by nature and corresponding core peak magnetic field density produced. At this point, the dissipated energy for the inductive component versus frequency can be predicted. Mathematical regressions from the energies results from the FEA tool were calculated; thus, the eddy current is divided into the energy at the boundary (10) and the core, (11) and the energy for hysteresis is defined in (12).

$$
\begin{aligned}
& E_{\text {surface }}=k_{S} \cdot f . \\
& E_{\text {core }}=k_{C} \cdot f . \\
& E_{\text {hys }}=k_{H} \cdot f^{2} .
\end{aligned}
$$

The dissipated energy for the component built with ferrite can be calculated by summing the energies (10)-(12). The specific coefficients, $k_{S}, k_{c}$ and $k_{H}$, are indicated in Table 4 for saturation and non-saturation status for the core used in this analysis and $f$ is the frequency. Based on the results, the dissipated energies from the eddy current are equal

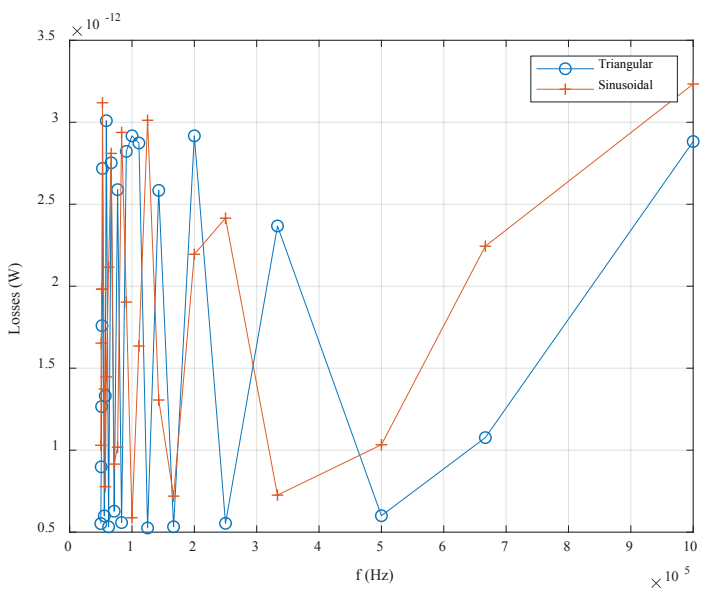

Figure 8 Comparison between A.1 vs C.1 (Eddy Loss at the core)

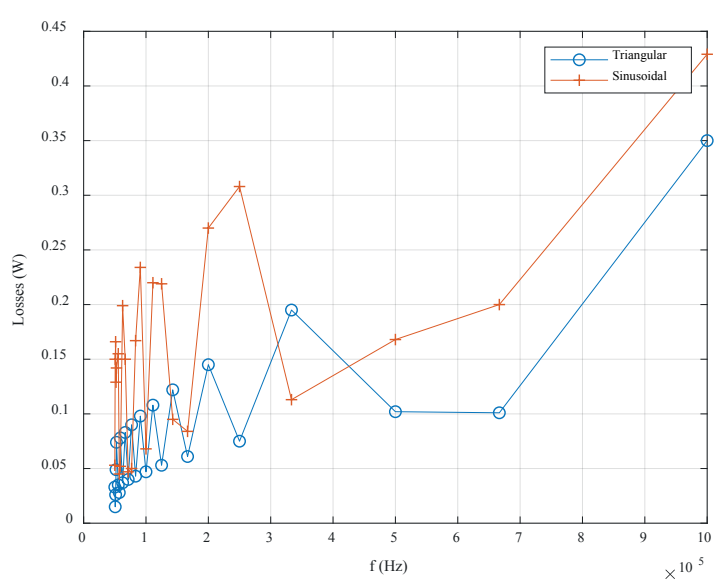

Figure 9 Comparison between A.1 and C.1 (Eddy Loss at the surface)

independent of the saturation; however, the hysteresis energy suffers a tendency to change when the core is in saturation.

The magnetic density peak for each signal according to the $I_{r m s}$ has been plotted in Figure 6 to demonstrate that there is a linear relationship between $\phi$ and $I_{r m s}$ for the analysed inductor.

The comparison of the hysteresis and eddy losses between the triangular signal (A.1) and the sinusoidal (C.1) is shown in the Figures 7-9. The tendency of the hysteresis loss of Signal C.1. is similar to the loss of Signal A.1. The values of the losses are in agreement with the $I_{r m s}$ of the signals. The values for the eddy losses from the core have similar values and are negligible from the eddy losses from the surface. The loss due to the eddy current for the core surface is larger in Signal C.1.

Since electronics engineers design inductors for working at a defined operation point in terms of frequency, it is necessary to have a dedicated analysis for this frequency operation point to obtain the difference for the output voltage for different signals.

In saturation status, the inductance (1) and resistance (2) for the core can be introduced in the simulator PSIM to 
obtain the voltage and current waveforms. If the core is not saturated, the winding inductance (3) and resistance (4) needs to be added into the model inductor in the simulator for a defined frequency range.

The original contribution of this work that it can modify the electrical parameters from one operating frequency point and $I_{r m s}$ to another without performing any FEM simulation using:

$$
\bar{P}=\frac{E}{T},
$$

where $E$ is $E_{\text {surface }}+E_{\text {core }}+E_{\text {hys }}$, calculated previously, and T is $1 / f$ to obtain the resistance. The inductance modification according to the frequency and $I_{r m s}$ is shown in Figure 6 with a linear relationship. With these results, it comes back to Equations (1)-(2) to obtain $R$ and $L$ at the desired frequency and signal for the core.

\section{Conclusions}

A model of an equivalent electrical circuit y designed for inductors made with 3C90 core used with triangular waveforms is presented in this manuscript.

The electrical parameters for the core and the coil, depending on the saturation status, have been estimated using a 3D FEM-model from $15 \mathrm{kHz}$ to $1 \mathrm{GHz}$. The 3D model was used to involve all the high-frequency effects in the analysis that cannot be calculated in 2D.

This work focused on the behaviour of the core power loss for toroidal components excited by triangular signals (9 different triangular signals were selected).

Determining the core power loss was divided by nature and they were not calculated for the Steinmez Equation.

The first conclusion of this paper is that the tendency of the energy dissipated is linear with the frequency for eddy losses and quadratic for hysteresis losses. The specific coefficients for the case shown in the paper are dependent on the $I_{r m s}$ and independent on the triangular shape excitation.

A comparison between the triangular and sinusoidal waveforms is presented along with the long-term effect that is not dependent on the signal nature and depends on the value of $I_{r m s}$.

The original contribution of this study is the capacity to modify the electrical parameters in the simulator PSIM according to the frequency point and $I_{r m s}$ using the conclusions in this paper, as indicated in Equation (13) and Figure 6 where the evolution of $\mathrm{R}$ and $\mathrm{L}$ for the Toroidal inductor depend on the frequency and current, without developing a new 3D FEM analysis to calculate the output waveforms.

\section{Acknowledgement}

This research has been supported by the Junta de Extremadura, under project IB18067 (with support of European Regional Development Fund) and by the Ministry of Education, Youth and Sports of the Czech Republic under the project OP VVV Electrical Engineering Technologies with High-Level of Embedded Intelligence CZ.02.1.01/0.0/0. 0/18_069/0009855 and by funding program of the University of West Bohemia number SGS-2018-009.

\section{Appendix}

Appendixes I and II where the evolution of the core loss and magnetic field density are plotted depending on the input current used for the FEM analysis are at the end of the paper.

\section{References}

[1] FISH, G. E. Soft magnetic materials. Proceedings of the IEEE [online]. 1990, 78(6), p. 967-972. ISSN 0018-9219. Available from: https://doi.org/10.1109/5.56909

[2] SNELING, E.C. Soft ferrites: properties and applications. 2. Ed. Oxford, U.K.: Butterworths, 1998. ISBN 978-0408027601,

[3] MOHAN, N.. UNDELAND, T. M.. ROBBINS, W. P. Power electronics: converters, applications and design. 3. ed. Hoboken, NJ: Wiley, 2002. ISBN 978-0-471-22693-2.

[4] KOLEDINTSEVA, M. Y. Soft ferrites for EMC applications. In: IEEE Symposium on Electromagnetic Compatibility, Signal Integrity and Power Integrity EMC, SI \& PI 2018 : proceedings. IEEE. 2018. p. 1-31.

[5] DAKOVA, L., FUZER, J., DOBAK, S., KOLLAR, P., OSADCHUK, Y. G., STRECKOVA, M., FABEROVA, M., BURES, R., KUREK, P., VOJTKO, M. Analysis of magnetic losses and complex permeability in novel soft magnetic composite with ferrite nanofibers. IEEE Transactions on Magnetics [online]. 2018, 54(12), p. 1-6. ISSN 0018-9464, eISSN 1941-0069. Available from: https://doi.org/10.1109/tmag.2018.2866814

[6] RIMAL, H. P. Dynamic model of soft ferrites for avionic applications. In: IEEE 4th International Forum on Research and Technology for Society and Industry RTSI 2018 : proceedings. IEEE. 2018. ISBN 978-1-5386-6282-3, p. 1-5.

[7] TRELA, K., GAWRYLCZYK, K. M. Frequency response modeling of power transformer windings considering the attributes of ferromagnetic core. In: International Interdisciplinary PhD Workshop IIPhDW 2018 : proceedings [online]. IEEE. 2018. p. 71-73. Available from: https://doi.org/10.1109/IIPHDW.2018.8388328 
[8] MATSUMORI, H., SHIMIZU, T., WANG, X., BLAABJERG, F. A practical core loss model for filter inductors of power electronic converters. IEEE Journal of Emerging and Selected Topics in Power Electronics [online]. 2018, 6(1), p. 29-39. ISSN 2168-6777. Available from: https://doi.org/ 10.1109/JESTPE.2017.2761127

[9] HE, R., ZHANG, Y., ZHANG, D., XIE, D. An improvement of core losses estimation model in power electronic transformer. In: IEEE Student Conference on Electric Machines and Systems 2018 : proceedings. IEEE. 2018. p. 1-5.

[10] ZEGADI, L., ROUSSEAU, J. J., ALLARD, B., TENANT, P., RENAULT, D. Model of power soft MnZn ferrites, including temperature effects. IEEE Transactions on Magnetics [online]. 2000, 36(4), p. 2022-2032. ISSN 0018-9464, eISSN 19410069. Available from: https://doi.org/10.1109/20.875308

[11] WILSON, P. R., ROSS, J. N., BROWN, A. D. Modeling frequency-dependent losses in ferrite cores. IEEE Transactions on Magnetics [online]. 2004, 40(3), p. 1537-1541. ISSN 0018-9464, eISSN 1941-0069. Available from: https://doi.org/10.1109/TMAG.2004.826910

[12] SHIXIA, M., HONGFU, W., JUNXIAN, H., TIEZHU, W. Fast electromagnetic transient simulation model of photovoltaic power system. In: International Conference on Power System Technology POWERCON 2018 : proceedings. 2018. p. 286-291.

[13] COSSART, Q., COLAS, F., KESTELYN, X. Simplified converters models for the analysis and simulation of large transmission systems using 100\% power electronics. In: 20th European Conference on Power Electronics and Applications EPE'18 ECCE Europe 2018 : proceedings. IEEE. 2018. p. P.1-P.10.

[14] KULMANOV, V., ANUCHIN, A., OSTRIROV, V., RUSAKOV, A., VAGAPOV, Y. Simulation and testing of a power converter for aircraft AC electric power generation system using software elimination of higher harmonics. In: 53rd International Universities Power Engineering Conference UPEC 2018 : proceedings [online]. IEEE. 2018. p. 1-6. Available from: https://doi.org/10.1109/UPEC.2018.8541922

[15] GONZALEZ-TEODORO, J. R., PRIETO, R., ASENSI, R. Simplifications in 3D high-low frequency models of multiwinding magnetic components (EE \& toroidal cores). International Jourmal of Magnetics and Electromagnetism [online]. 2015, 1(1), p. 1-7. ISSN 2631-5068. Available from: https://doi.org/10.35840/2631-5068/6503

[16] Data handbook of ferroxcube - Ferroxcube International Holding B.V. [online] [Viewed 2017-11-09]. Available from: https://www.ferroxcube.com/en-global/download/index

[17] SALAS, R. A., PLEITE, J. Equivalent electrical model of a ferrite core inductor excited by a square waveform saturation and power losses for circuit simulation. IEEE Transactions on Magnetics [online]. 2013, 49(7) p. 4257-4260. ISSN 00189464, eISSN 1941-0069. Available from: https://doi.org/10.1109/TMAG.2013.2238223

[18] ASENSI, R., PRIETO, R., COBOS, J. A., UCEDA, J. Modeling high-frequency multiwinding magnetic component using finite-element analysis. IEEE Transactions on Magnetics [online]. 2007, 43(10), p. 3840-3850. ISSN 0018-9464, eISSN 1941-0069. Available from: https://doi.org/10.1109/TMAG.2007.903162

[19] ALBACH, M.. DURBAUM, T., BROCKMEYER, A. Calculating core losses in transformers for arbitrary magnetizing currents - a comparison of different approaches. In: IEEE Power Electronics Specialists Conference : proceedings. 1996. p. 1463-1468.

[20] ANSYS Maxwell - ANSYS, Inc. [online]. Available from: https://www.ansys.com/es-es/products/electronics/ansysmaxwell 


\section{Appendix I}

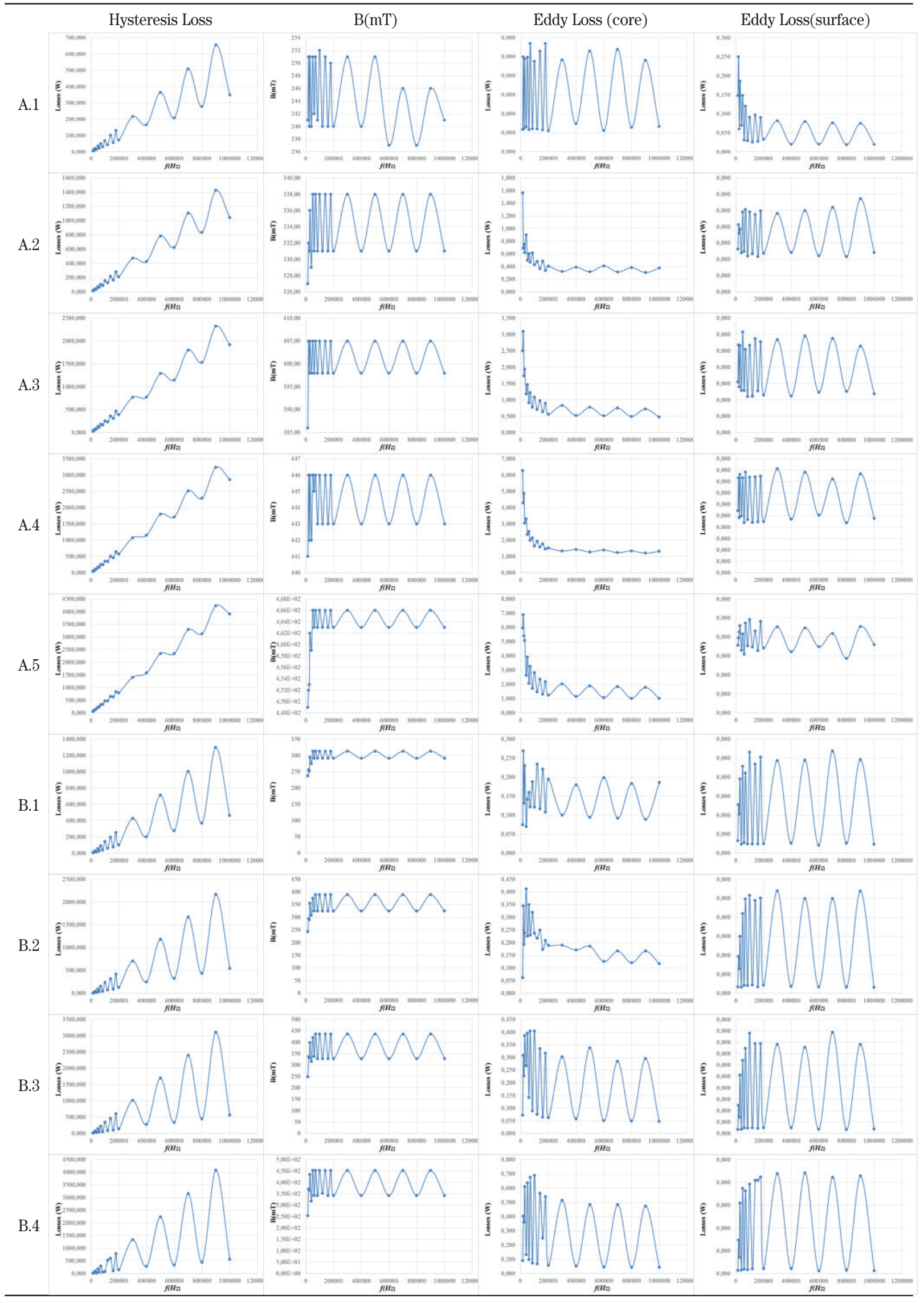


Appendix II

A. 1
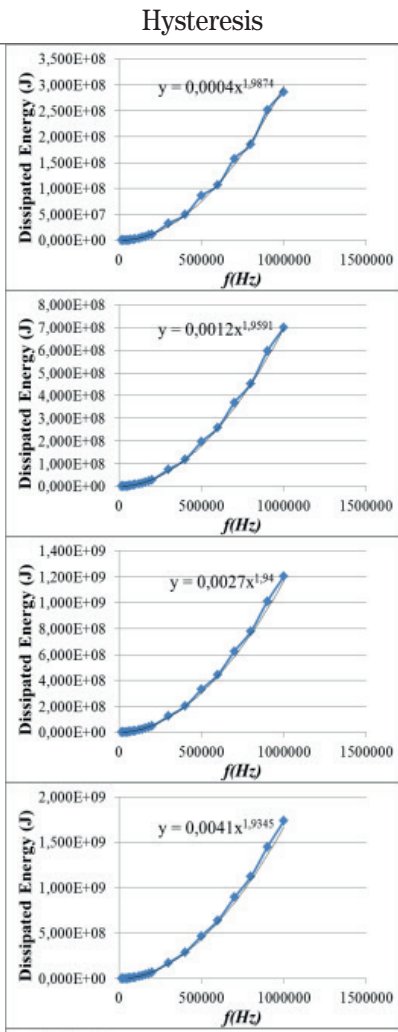

A. 4

A. 5

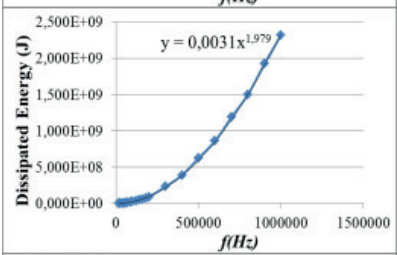

B.1

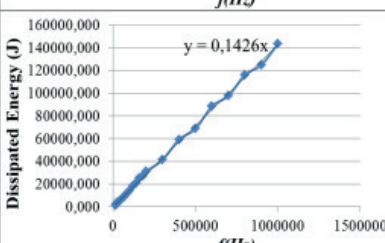

$\begin{array}{rc}0 & 500000 \quad f(H z) \\ 1,200 E+09 & 1000000 \\ \end{array}$

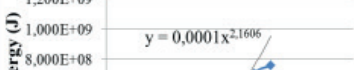

这,

B.2
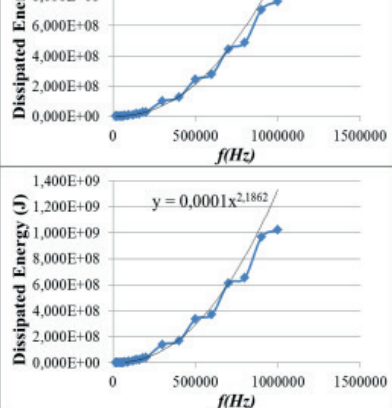

B.3

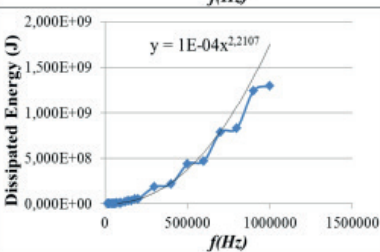

Eddy Loss (core)

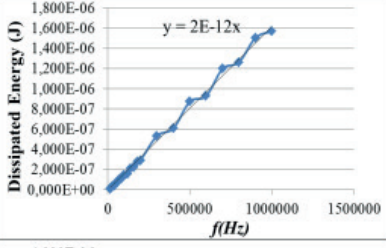

$4,000 \mathrm{E}-06$

3, 3,500E-06

3, $3,000 \mathrm{E}-06$

2,500E-06

2,000E-06

1,500E-06

글 $1,000 \mathrm{E}-06$

产 $5,000 \mathrm{E}-07$
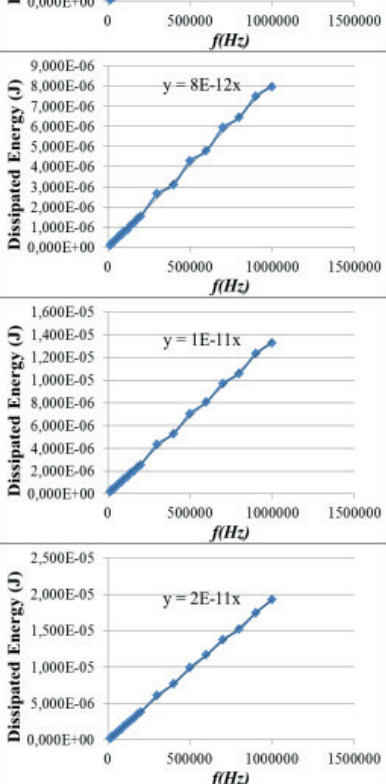

$f(H z)$

ב $2,500 \mathrm{E}-06 \quad \mathrm{y}=3 \mathrm{E}-12 \mathrm{x}$

$2,000 \mathrm{E}-0$

至 $1,500 \mathrm{E}-0$

छ $1,000 \mathrm{E}-06$

$5,000 \mathrm{E}-0$
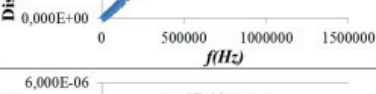

$\widehat{5}_{5,000 \mathrm{E}-06}^{6,000 \mathrm{E}-06} \quad \mathrm{y}=5 \mathrm{E}-12 \mathrm{x}$

4,000E-06

4,000E-06

2,000E-06

$1,000 \mathrm{E}-06$

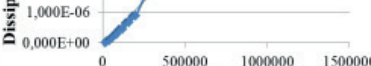

$500000 \quad 1000000-1500000$

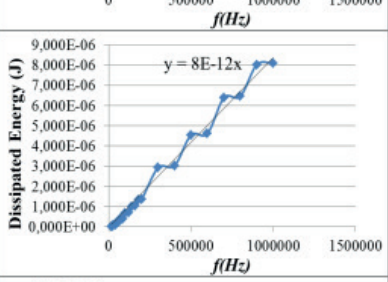

1,400E-05

S $1,200 E-05 \quad y=1 E-11 x$

ia $1,000 \mathrm{E}-05$

$8,000 \mathrm{E}-06$

6,000E-06

$4,000 \mathrm{E}-06$

$2,000 \mathrm{E}-06$

$0,000 \mathrm{E}+00$

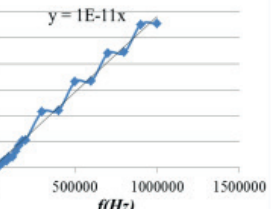

Eddy Loss(surface)

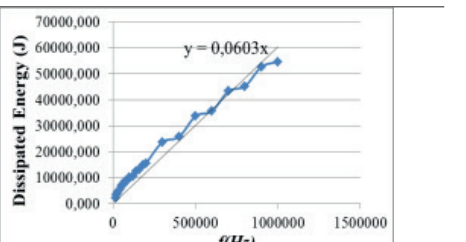

450000,000
400000,000
350000,000

350000,000

250000,000

200000,000

¿ 1500000,000

尊 100000,000

势 50000,000

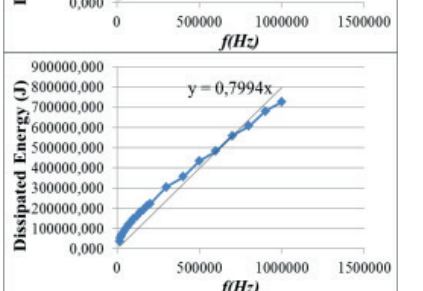

1800000,000

3.

1200000,000

sis. 1000000,000

800000,000
600000,000

600000,000

200000,000
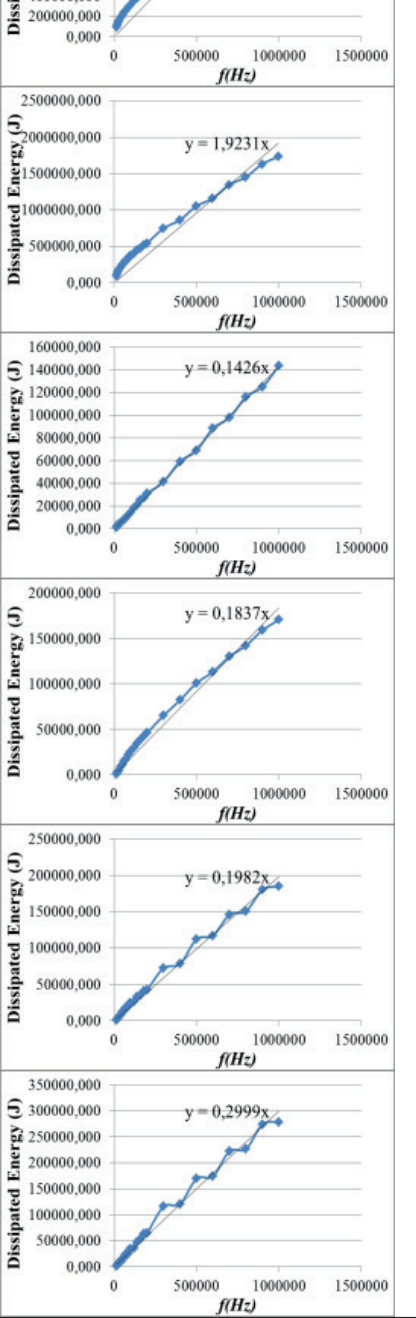